\title{
REPRESENTASI UNGKAPAN-UNGKAPAN BAHASA LAMAHOLOT LINGKUNGAN KELAUTAN MASYARAKAT DESA BAHINGA TERHADAP PENINGKATAN NILAI-NILAI PENDIDIKAN KARAKTER
}

\author{
Fransiska Jone Mare \\ Institut Keguruan dan Teknologi Larantuka - Program Studi Bahasa Inggris \\ chikamare9@gmail.com
}

\begin{abstract}
The article explains about the representation of maritime metaphors of Lamaholot Language of Bahing a Community in Increasing the values of educational character. The aims of this article are to find the kinds of maritime-metaphor and to find the representation of those metaphors in building the students' characters. Research approaches in this article is descriptive qualitative. The data retrieved by using observation and interview as main data and secondary data is taken from the thesis. The results show that there are nine maritime metaphors of Lamaholot Language of Bahinga Community can be used in increasing the values of educational character.
\end{abstract}

Key Words: Maritime-Metaphors and the values of educational characters

\begin{abstract}
ABSTRAK
Artikel ini menjelaskan tentang representasi metafora maritim Bahasa Lamaholot Komunitas Bahinga dalam Meningkatkan nilai-nilai karakter pendidikan. Tujuan dari artikel ini adalah untuk menemukan jenis metafora maritim dan untuk menemukan representasi metafora tersebut dalam membangun karakter siswa. Pendekatan penelitian dalam artikel ini adalah deskriptif kualitatif. Data yang diambil dengan menggunakan pengamatan dan wawancara sebagai data utama dan data sekunder diambil dari tesis. Hasil penelitian menunjukkan bahwa ada sembilan metafora maritim Bahasa Lamaholot Komunitas Bahinga dapat digunakan dalam meningkatkan nilai-nilai karakter pendidikan.
\end{abstract}

Kata Kunci: Maritim-Metafora dan nilai-nilai karakter pendidikan

\section{PENDAHULUAN}

Kemajuan teknologi informasi dan industri yang berkembang terus-menerus dalam peradaban dunia, berdampak pula terhadap karakter manusia terutama karakter generasi muda. Generasi muda merupakan tunas-tunas bangsa yang perlu diberikan pembinaan secara berkelanjutan pada karakter mereka agar siap berseluncur bersama kemajuan teknologi dengan tanpa meninggalkan jati diri dan integritasnya sebagai manusia berbudaya. Melihat meningkatnya krisis moral di kalangan generasi muda dewasa ini, seperti pergaulan bebas, penipuan, penggunaan obat-obatan terlarang, tawuran, pencurian terencana, penculikan dan kekerasan terhadap anak dan remaja, pornografi, serta masih banyak tindakan-tindakan negatif lain yang berkembang biak dengan suburnya telah memantik pemerintah untuk melakukan pencegahan dini agar dapat menyelamatkan generasi bangsa dari ketersesatan zaman melalui Pendidikan karakter.

Menurut Lickona, dalam Samani dan Hariyanto, 2011:44, Pendidikan karakter adalah sebuah upaya yang disengaja untuk memperbaiki karakter peserta didik sejak dini agar dapat membantu mereka memahami, peduli dan bertindak dengan landasan-landasan nilai etis. Pendidikan sebagai upaya yang disengaja untuk memperbaiki karakter peserta didik kemudian dimaktumkan pada salah satu program prioritas Presiden Joko Widodo dalam Perpres (Peraturan Presiden) nomor 87 tahun 2017 tentang Penguatan Pendidikan Karakter (PPK). 
Adapun dimensi pendidikan karakter yang dicetuskan pemerintah meliputi Olah hati (Etik), Olah pikir (Literasi) Olah rasa (Estetik) dan Olah raga/ kinesetik (web.kominfo.go.id). Kelima dimensi tersebut diharapkan dapat meningkatkan nilai-nilai utama karakter peserta didik, yakni (1) Beriman kepada Allah pencipta alam semesta (2) bertanggung jawab, tertib dan tidak bergantung pada orang lain, (3) memiliki jiwa jujur (4) memiliki tenggang rasa dan toleransi, (5) cinta kasih, suka tolong menolong dan setia (6) Berprinsip, inovatif, pantang menyerah, (7) bersikap adil dan berani (8) berjiwa besar, (9) toleransi, cinta damai dan persatuan (Megawangi, 2001: 53 dalam Prosiding Seminar Nasional). Penguatan karakter ini dapat dikembangkan melalui pengetahuan, direalisasikan dalam tindakan untuk menjadikannya suatu kebiasaan. Gerakan tersebut perlu dilakukan secara terencana, berkelanjutan dan bertanggung jawab dalam setiap ruang tumbuh peserta didik yakni sekolah, rumah dan lingkungan masyarakat.

Sekolah merupakan rumah kedua dalam menempuh pendidikan formal bagi peserta didik. Sekolah dipercaya mampu menghasilkan manusia berkarakter dengan menerapkan strategi dan metode yang efektif dalam pembelajaran. Metode-metode belajar efektif perlu memperhatikan konteks situasi dan tempat dimana para siswa bertumbuh dan berkembang serta memperhatikan situasi-situasi yang sedang terjadi dalam dunia modern secara umum. Guru dapat menerapkan aneka metode pembelajaran namun metode yang mungkin efektif dalam menumbuhkan karakter siswa adalah yang berkonteks budaya. Pembelajaran yang menggandeng konteks budaya lokal dianggap penting karena setiap budaya lokal memiliki nilai-nilai moral tinggi yang dijunjung oleh masyarakat setempat sehingga peserta didik dapat menumbuhkan rasa cinta pada budaya lokal serta menghasilkan generasi yang dapat mengaktualisasikan nilai-nilai budaya dalam kehidupan sehari-hari.

Berbicara budaya tidak dapat lepas dari kehadiran manusia sebab hanya manusia yang memiliki kebudayaan. Hadirnya kebudayaan disebabkan oleh sebuah tindakan manusia dalam memberikan simbol terhadap sesuatu dalam rangka berkomunikasi dengan sesama dalam satu guyub tutur. (Ahimsa-Putra, 2004:29). Kehadiran simbol dalam komunitas guyub tutur dapat berupa tulisan, tuturan, seni dan tanda (Tumanggor Rusmin, Kolis Ridho, Nurochmin, 2010:27). Setiap komunitas guyup tutur tentu memiliki pemaknaan yang berbeda-beda terkait kehadiran simbol atau tanda-tanda tersebut termasuk kelompok masyarakat yang berada di Desa Bahinga, Kecamatan Tanjung Bunga. Masyarakt Desa Bahinga menggunakan bahasa lamaholot dalam komunikasi sehari-hari yang kemudian dikenal dengan Bahasa Lamaholot dialek Lamaojan.

Dalam kehidupan sehari-hari, masyarakat desa melakukan aktifitas di laut dan di darat. Letak Desa Bahinga yang cukup strategis antara laut dan gunung menyebabkan masyarakat desa memiliki kekayaan bahasa, teristimewa dalam menggunakan ungkapan-ungkapan atau majas. Ungkapan diartikan sebagai penggunaan kata atau beberapa kata yang bukan arti sebenarnya, melainkan sebagai bentuk kiasan atau lukisan terhadap sesuatu yang memiliki persamaan atau perbandingan (Sudaryat,2009:89). Kekayaan ungkapan atau majas yang terdapat di lingkungan masyarakat desa merupakan representasi dari pemilihan leksikonleksion laut yang dianggap memiliki sifat, ciri-ciri dan kepribadian mirip seperti manusia. Kehadiran ungkapan-ungkapan tersebut membuktikan bahwa nenek moyang masyarakat Desa Bahinga memiliki hubungan yang sangat dekat dengan alam.

\section{METODOLOGI}

Penelitian ini menggunakan metode deskriptif kualitatif. Data penelitian bersumber dari data primer dan data sekunder. Data utama (Primer) diambil dari narasumber di lapangan ketika 
melakukan wawancara. Data pendukung (Sekunder) diambil dari data pustaka berupa Tesis. Data yang terkumpul kemudian diolah, diklasifikasikan, dan dianalisis berdasarkan pokokpokok pembahasan yang berkaitan dengan peningkatan nilai-nilai pendidikan karakter.

\section{PEMBAHASAN}

Kearifan lokal merupakan warisan budaya lokal yang memiliki nilai kebijaksanaan tinggi, pandangan hidup, nilai, norma serta penuh hikmat. Terdapat beberapa ungkapan leksikon kelautan, yang dipandang perlu diterapkan dalam sistem pembelajaran guna menumbuhkan karakter-karakter peserta didik yang berintegritas dan berbudaya. Ungkapan-ungkapan tersebut adalah:

\section{Kuno dule lali wai, loma weli muko ono.}

Secara harafia arti dari ungkapan tersebut adalah Ikan Kuno (ikan teri) berenang di air, tersesat di dalam rumpun pisang. Makna ungkapan di atas adalah sudah merasa senang di kampung orang, lupa akan kampung halaman sendiri. Majas ini menggambarkan sifat ikan teri dimana pada saat berenang mencari makan, ia menemukan begitu banyak makanan di antara rumpun pisang sehingga ia lupa kembali ke laut.

Pandangan hidup dari ungkapan ini mengajarkan kita agar jangan bersikap serakah atau rakus pada kekayaan yang akan menyebabkan sesuatu yang buruk terjadi pada kita akibat lupa identitas diri dan kampung halaman. Ungkapan ini memuat nilai pendidikan karakter dalam dimensi etik dan estetis yakni diharapkan peserta didik menjadi pribadi yang memiliki iman yang teguh, bermoral dan berbudaya dengan memiliki karakter yang cinta akan Tuhan, penuh kasih sayang, peduli dan rendah hati.

\section{Liko no'o tia, horok no'o bawo}

Secara harafia arti dari ungkapan tersebut adalah Dilindungi oleh ikan Tia, di rangkul dengan ikan kakap. Makna ungkapan di atas menyatakan hidup dalam kebersamaan yang penuh denga toleransi. Ungkapan ini menggambarkan dua jenis ikan yang berbeda, baik bentuk, sikap, mau pun fisiknya. Konon kedua ikan ini dipercayai oleh leluhur merupakan sahabat dimana kedua jenis ikan ini selalu bersama-sama dan jarang bertengkar seperti ikan-ikan yang lain.

Pandangan hidup dari ungkapan ini mengajarkan kita agar selalu menciptakan toleransi, kebersamaan dan cinta kasih tanpa membedakan jenis kelamin, ras, atau golongan. Ungkapan ini memuat nilai pendidikan karakter dalam dimensi etik, estetik dan literasi yakni peserta didik diharapkan dapat memiliki karakter rasa syukur, tenggang rasa, suka menolong tanpa membedakan agama, ras atau golongan dengan memiliki karakter nasionalis, toleransi dan religius.

\section{Khole dai tama wuwo, bawo dai gere wuwo.}

Arti dari ungkapan di atas secara harafiah adalah Ikan khole datang masuk bubu, Ikan bawo datang naik bubu (bubu merupakan salah satu alat tradisional menangkap ikan yang terbuat dari anyaman bambu berbentuk kotak persegi panjang yang ramah lingkungan). Makna ungkapan ini adalah meski pun kita berbeda ras, budaya, kedudukan dan golongan, kita adalah satu kelompok manusia yang harus saling membantu dan bekerja sama dalam menghadapi tantangan demi kebaikan bersama. Ungkapan ini menggambarkan dua jenis ikan, yang memiliki fisik indah, baik warna mau pun bentuk tubuh, dan ke dua jenis ikan ini selalu 
bermusuhan, namun ketika ikan-ikan ini terperangkap di dalam bubu mereka akan bekerja sama, bersatu, melakukan berbagai cara agar dapat keluar dari perangkap tersebut.

Pandangan hidup dari ungkapan ini mengajarkan kita bahwa persaingan, kebencian, iri hati karena berbeda atau memiliki kelebihan tidak membawa kebaikan bagi kita. Persaingan dan kebencian bukan menjadi alasan untuk mengundang perpecahan atau pertengkaran. Sebagai manusia yang hidup dalam satu komunitas, mengharapkan keselamatan, ketenangan, kedamaian dan kebahagiaan adalah keharusan. Kita tentu akan menolak hal-hal yang mendatangkan perpecahan, apalagi yang mengancam keselamatan diri kita. Ungkapan ini memuat nilai-nilai pendidikan karakter dalam dimensi etik, estetik, literasi dan kinesetik yakni peserta didik diharapkan dapat memiliki rasa cinta akan Tuhan, cinta damai, cinta tanah air dan rela berkorban demi kebaikan bersama.

\section{Krogo bao dore ole lali, bao balik role take}

Secara harafiah arti ungkapan ini adalah ikan krogo bao, ikut ombak ke bawah, terampung, kembali atau tidak. Makna dari ungkapan ini adalah melukiskan tentang sifat manusia yang mudah dipengaruhi dan tidak tetap pada pendirian. Ungkapan ini menggambarkan sikap ikan krogo bao, yang mudah terbawa arus, terombang-ambing di laut, kemana saja arus pergi, ikan ini akan selalu ikut.

Pandangan hidup dari ungkapan ini mengajarkan kita sebagai manusia kita harus memiliki prinsip hidup, mandiri dan jujur. Ungkapan ini memuat nilai-nilai Pendidikan karakter dalam dimensi etik, estetik, yakni para peserta didik diharapkan memiliki sikap pantang menyerah, jujur, kuat serta berpendirian teguh, mandiri, jujur dan beriman kepada Tuhan.

\section{Mo pana peke go hama ne ketili kride}

Arti ungkapan ini secara harafia adalah kamu pergi meninggalkan saya seperti siput ketili yang kurus. Ungkapan ini melukiskan kegelisahan atau ungkapan ratapan dari seorang istri atau anak yang ditinggalkan oleh orang-orang terkasih (kematian, merantau tak kenal pulang) dan membiarkan dia sebatang kara sehingga ia dituntut untuk mempertahankan hidupnya sendirian. Ungkapan ini menggambarkan sifat dari siput Ketili. Siput ini hidup di laut dalam dan dangkal. Siput ini selalu ditemukan sendirian, berpisah dari siput-siput lain.

Pandangan hidup dari ungkapan ini, mengajarkan kita untuk selalu beriman kepada Tuhan, bertanggung jawab, tegar, kuat dan pantang menyerah. Ungkapan ini memuat nilainilai karakter dalam dimensi etik, kinestik yakni para peserta didik dapat menjadi manusia beriman, berakhlak, kuat, tanggung jawab, mandiri dan suka menolong.

\section{Klepa ake ono woho, krage ake wutu}

Arti harafia atas ungkapan ini adalah Ikan klepa muka atau belakang, tulang daun lontar yang bagian dalamnya kasar dan bagian luarnya mulus. Makna dari ungkapan ini adalah jangan menjadi manusia yang munafik. Ungkapan ini menggambarkan sifat ikan dan sifat daun lontar. Sifat ikan klepa ini, manusia sulit membedakan ikan klepa ketika berada di laut karena bagian belakang dan bagian depan ikan klepa memiliki tekstur yang sama sedangkan daun lontar, memiliki tekstur yang berbeda yakni bagian luarnya mulus namun bagian dalamnya kasar. 
Pandangan hidup dari ungkapan ini mengajarkan kita untuk menjadi manusia yang jujur, tulus dan tidak munafik. Ungkapan ini memuat nilai karakter dalam dimensi etik dan estetik yakni para peserta didik dapat menjadi manusia yang jujur, taat, dan tidak muka belakang dengan memiliki karakter yang bermoral, beriman, berintegritas budaya.

\section{Tahik gere kwoko, kedi mo reto}

Arti harafia atas ungkapan di atas adalah air laut naik sampai di leher baru kamu kaget. Makna dari ungkapan ini adalah jangan suka menunda pekerjaan. Ungkapan ini menggambarkan sifat manusia yang cenderung menganggap remeh segala sesuatu dan suka menunda-nunda pekerjaan sehingga pada waktu tertentu dia kesulitan mengontrol, kerepotan, tak dapat bernapas sebab air laut sudah melampau lehernya.

Pandangan hidup dari ungkapan ini mengajarkan kita untuk selalu setia akan pekerjaan, tertib, disiplin, kuat selalu memiliki semangat mencari tahu hal yang tidak diketahui. Ungkapan ini memuat nilai karakter dalam dimensi estetik, literasi, dan kinesetik yakni para peserta didik dapat menjadi manusia yang disiplin, mandiri dan tertib.

\section{Na hama kebeku}

Arti harafia atas ungkapan di atas adalah dia seperti ikan kebeku. Makna dari ungkapan ini adalah jangan menjadi orang yang malas, bodoh dan pasif. Ungkapan ini menggambarkan sifat ikan kebeku yang selalu diam di tempat ketika ada musuh sebab ikan ini makanan pokoknya adalah pasir laut sehingga dia tidak perlu pergi mencari makan.

Pandangan hidup dari ungkapan ini mengajarkan kita untuk memiliki sikap rajin, kreatif, inovatif dan tidak bermental instan.Ungkapan ini memuat nilai karakter dalam dimensi kinesetik dan estetik yakni para peserta didik dapat menjadi pribadi yang berkarakter inovatif dan kreatif, tidak cepat puas, pantang menyerah dan cerdas.

\section{Nuhu nae hama ketuko}

Arti harafia atas ungkapan di atas adalah mulutnya seperti ikan ketuko. Makna dari ungkapan ini adalah jangan menjadi orang yang cerewet, cemburu dan iri hati. Ungkapan ini menggambarkan sifat ikan ketuko dimana ikan ini selalu berkelompok di laut. Ikan ini akan selalu membuka mulutnya bermain bersama ombak dan suka menyemburkan air.

Pandangan hidup dari ungkapan ini mengajarkan kita agar tidak boleh ikut campur masalah atau persoalan orang lain, tidak boleh bergosip dan menceritakan kejelekan atau kesusahan orang. Ungkapan ini memuat nilai karakter etik, estetik dimana para peserta didik dapat menjadi pribadi yang dapat menghargai dan menghormati orang lain, empati terhadap penderitaan orang dan selalu bersyukur.

\section{KESIMPULAN}

Berdasarkan hasil pembahasan di atas, maka dapat disimpulkan bahwa nenek moyang masyarakat Desa Bahinga memiliki hubungan yang dekat dengan lingkungan alam laut. Hal tersebut dilihat dari kekayaan ungkapan- ungkapan lingkungan kelautan yang dapat melukiskan sifat dan karakter manusia. Kekayaan ungkapan-ungkapan ini sebetulnya memiliki nilai-nilai kearifan lokal yang tinggi dan patut untuk dipertahankan. Terdapat sembilan ungkapan-ungkapan yang berkaitan dengan lingkungan kelautan. Ungkapan-ungkapan tersebut 
dinilai dapat meningkatkan nilai-nilai karakter peserta didik sebab ungkapan tersebut sangat dekat dengan kehidupan peserta didik setiap hari.

Ungkapan-ungkapan tersebut adalah sebagai berikut. (1) Kuno dule lali wai, loma weli muko ono, Ungkapan ini merepresentasikan nilai karakter yang cinta akan Tuhan, penuh kasih saying, peduli dan rendah hati, (2) Liko no'o tia, horok no'o bawo, Ungkapan ini merepresentasikan nilai karakter yang beriman akan Allah, tolerasi, dan kerja sama, (3) Khole dai tama wuwo, bawo dai gere wuwo, Ungkapan ini merepresentasikan nilai karakter yang cinta akan Tuhan, cinta damai, cinta tanah air dan rela berkorban demi kepentingan bersama, (4) Krogo bao dore ole lali, bao balik role take, Ungkapan ini merepresentasikan nilai karakter manusia yang memiliki prinsip teguh, pantang menyerah, jujur dan kuat, (5) Mo pana peke go hama ne ketili kride, Ungkapan ini merepresentasikan nilai karakter tanggung jawab, tegar, kuat dan mandiri, (6) Klepa ake ono woho, krage ake wutu, Ungkapan ini merepresentasikan nilai karakter manusia yang jujur, taat, dan tidak munafik, (7) Tahik gere kwoko, kedi mo reto, Ungkapan ini merepresentasikan nilai karakter peserta didik yang disiplin, mandiri dan tertib, (8) Na hama kebeku, Ungkapan ini merepresentasikan nilai karakter yang berkarakter inovatif dan kreatif, tidak cepat puas, pantang menyerah dan cerdas, (9) Nuhu nae hama ketuko, Ungkapan ini merepresentasikan nilai karakter yang dapat menghargai dan menghormati orang lain, empati terhadap penderitaan orang dan selalu bersyukur.

Ungkapan-ungkapan tersebut merupakan warisan kearifan lokal yang kaya akan nilainilai kehidupan sehingga sangat penting untuk diterapkan dalam dunia pendidikan teristimewa dalam mata pelajaran Bahasa Indonesia dan Muatan Lokal. Ungkapan-ungkapan tersebut dapat memenuhi tujuan pendidikan karakter yang dicetuskan oleh Presiden Joko Widodo yakni mencakupi nilai etik, estetik, literasi dan kinesetik. Diharapkan dengan diterapkan metode pembelajaran yang berbasis kearifan lokal maka dapat meningkatkan kesadaran peserta didik untuk menjadi manusia yang berintegritas dan berbudaya.

\section{DAFTAR PUSTAKA}

Tumanggor Rusmin, Ridho kholis, Nurochim. (2010). Ilmu Sosial dan Budaya Dasar. Prenadamedia. Jakarta.

Habibi Mujtaba. (2015). Revolusi Pendidikan Karakter Bangsa dalam Prosiding Seminar Nasional. Fakultas Ilmu Sosial Universitas Negeri Malang. Semarang.

Mare Fransiska. (2018). Khazanah Ekoleksikon dan Mitos Kebaharian Guyup Tutur Lamaholot Desa Bahinga. Thesis

$\underline{\text { www.kemendikbud.go.id }}$

web.kominfo.go.id/sites/default/files/CerdasBerkarakter 